Por fim, a coletânea Mobilização social na Amazônia vem propor uma possível contribuição para o fazer antropológico. Um dos exercícios marcantes da Antropologia foi o de deixarmos de falar por nossos "objetos de pesquisa", em uma relação que era eminentemente vertical e etnocêntrica. Atualmente, lidamos com interlocutores com os quais o diálogo se apresenta cada vez mais encorajado e o "retorno" das pesquisas cada vez mais fecundo e cobrado por eles próprios. Porém, além disso, esta coletânea atesta que não apenas os resultados devem ser tornados visíveis em conjunto, mas o fazer-se ouvir é cada vez mais uma ampliação das práticas dos sujeitos que descobrem a sua audibilidade, não só no texto acadêmico, mas na imagem e na oralidade, marcando a sua posição de autoria e ressonância política.

DOI http://dx.doi.org/10.1590/0104-93132015v21n1p224

LEITE, Yonne de Freitas. 2012. Línguas indígenas: memórias de uma pesquisa infinda. Bruna Franchetto \& Thiago Coutinho-Silva (orgs.). Rio de Janeiro: 7Letras. 260 pp.

\section{Evandro Bonfim}

Pesquisador Dept $^{\circ}$ de Antropologia Museu Nacional-UFRJ

A figura do antropólogo como desbravador solitário há muito vem esmaecendo com a explicitação da série de mediações e agentes que fazem o ofício possível antes mesmo do aceite das populações nativas. Se missionários e antropólogos são, a contragosto dos últimos, "brothers under the skin" - como afirma Van der Geest - qual seria a relação entre eles e os linguistas? A interlocução própria dos companheiros de viagem parece ser adequada para descrever as contribuições mútuas entre os dois tipos de estudiosos, conforme mostra, para o caso brasileiro, o livro Línguas indígenas: memórias de uma pesquisa infinda com escritos de Yonne Freitas Leite, falecida no final de 2014. A coletânea de 16 artigos apresenta de forma condensada para público mais amplo a versão, no campo da Linguística, de uma das mais importantes incursões da Etnografia americanista, a saber, aquela realizada no âmbito do Museu Nacional/UFRJ, de onde saíram teorias de repercussão para a Antropologia atual. As pesquisas de Leite sobre o tapirapé representam um marco não só na constituição da ciência linguística no país, mas também do trabalho de campo em grupos indígenas.

Nos textos autobiográficos ("Memórias de uma aprendiz ingênua" e "A língua tapirapé. O caso de uma pesquisa infinda"), Leite conta sobre as felizes coincidências que a levaram a ter contato nos Estados Unidos com dados de línguas indígenas faladas em território brasileiro e que fizeram com que chegasse depois, pelas mãos de Roberto Cardoso de Oliveira, ao recém-criado Setor de Linguística do Departamento de Antropologia do Museu Nacional. A unidade estava a cargo do professor Mattoso Câmara, colega de Lévi-Strauss nos cursos de Roman Jakobson. A coroação dos acasos afortunados vem com a chegada aos Tapirapé, grupo falante de língua da família Tupi-Guarani que vive atualmente nos estados de Mato Grosso e Tocantins. A autora conta que, ao contrário da iniciação traumática que esperava, encontrou condições naturais favoráveis e boa recepção por parte dos indígenas e das pessoas que trabalhavam com eles, como as Irmãzinhas de Jesus.

As principais dificuldades surgiram dos poucos trabalhos, sobretudo em português, sobre os Tapirapé à época das primeiras visitas da pesquisadora à área. A falta de material etnográfico e a necessidade de descrição da língua 
a partir das configurações próprias do tapirapé - e não das teorias disponíveis, como ressalta a autora - deram margem à articulação entre a Linguística e a Antropologia que caracterizou grande parte do trabalho de Yonne Leite. Artigos como "Língua e Cultura" e "A política de institucionalização do campo das línguas indígenas brasileiras e o papel da Antropologia", presentes na coletânea, são mostras de tal preocupação que se estende para outros textos, como "De Homens, Árvores e Sapos: Forma, Tempo e Espaço em Tapirapé", em que autora apresenta o complexo sistema de dêixis e de classificadores tapirapé e o articula com a cosmologia nativa.

No entanto, a maior parte dos textos é dedicada à descrição linguística, tarefa que a autora realiza de forma bastante particular: sempre apresentando os ganhos e as desvantagens do referencial teórico do qual se utiliza e transitando entre as várias possíveis respostas aos problemas que planteia. Tais artigos são valiosos para todos os acadêmicos que pesquisam povos Tupi, visto que tanto os sete artigos sobre o tapirapé quanto os dois sobre o araweté possuem - quer como meta direta ou plano de fundo - o problema da organização interna ao grupo, principalmente da família Tupi-Guarani. Os compartilhamentos e as divergências de determinados elementos fonológicos ou sintáticos fazem com que os idiomas em questão, principalmente o araweté, se apresentem aparentados ora com determinado conjunto de línguas, ora com outro, abrindo espaço para mostrar que os critérios de filiação genética fornecidos pela Linguística Histórica não são suficientes para estabelecer as relações entre as línguas e os povos que as falam. O debate promovido por Leite excede as línguas particulares e toca em classificações bem aceitas para a família Tupi-Guarani, como as que caracterizam inúmeros idiomas do grupo como pertencentes ao tipo sintático ativo/não ativo proposto por Klimov. Em "As classes de verbos intransitivos em línguas da família Tupi-Guarani", a autora mostra como a divisão semântica tradicional entre verbos ativos e verbos de estado não se integra a fatos sintáticos como a incorporação e a composição através de morfemas de mudança de valência como causativos, fazendo-a considerar a separação entre verbos inergativos e inacusativos proposta por Hale \& Keyser.

Os artigos sobre o tapirapé, o araweté e a família Tupi-Guarani desvelam outro aspecto importante da obra de Yonne Leite que se soma às contribuições linguísticas: o valor do trabalho colaborativo e interdisciplinar. Muitos textos são assinados também pela linguista Márcia Dâmaso, atualmente professora do Museu Nacional, cuja descrição da língua assurini apresenta a questão da não configuracionalidade na família Tupi-Guarani. Leite aborda o tema a partir de uma característica interessante do tapirapé encontrada nas demais línguas da família, a aparente ordem livre dos constituintes (sujeito, objeto e verbo), discussão presente no texto "A ordem livre em algumas línguas da família Tupi-Guarani: em busca de uma proposta de análise". Já os artigos sobre o araweté partem da descrição preliminar realizada pelo etnólogo Eduardo Viveiros de Castro, cuja monografia sobre o povo Tupi, então recém-contatado, se inscreve como marco da americanística contemporânea.

Dois artigos da pesquisadora mostram preocupações mais amplas a partir da questão das línguas indígenas. Em "O Summer Institute of Linguistics - estratégias e ação no Brasil", a autora analisa o significado político da iniciativa missionária que oferecia apoio linguístico e pedagógico para estabelecer acordos com países com 
grupos nativos não cristianizados. Apesar da intensa atividade de ensino universitário nos anos iniciais do SIL no Brasil, a produção linguística dos integrantes da organização se mostra exígua, diante da quantidade de anos e de grupos indígenas com os quais trabalharam. Isto porque, a partir de 1969, o SIL passou a tratar diretamente com a Funai, apoiando-se basicamente na questão da alfabetização. A qualidade da maior parte dos trabalhos estava limitada pelo objetivo maior de reduzir a língua à forma ortográfica, necessária para a tradução da Bíblia. Segundo Leite, os resultados práticos do empreendimento são cartilhas nas quais a língua indígena aparece esvaziada de qualquer relevância e conexão com a vida indígena, trazendo muitas vezes conteúdo propagandístico do Estado brasileiro durante o período dos convênios oficiais, encerrados em 1977.

Em "O português brasileiro, uma língua criola", a autora comenta a hipótese da influência do substrato indígena na formação do português nacional. Dois focos importantes são tratados no decorrer do artigo: o papel das línguas francas de origem tupi (como o tupinambá e o nheegatu amazônico) e o português falado por indígenas em regiões multilíngues, como o Parque do Xingu. A autora conclui que certos fenômenos encontrados no português brasileiro (como a falta de concordância sujeito/verbo) não poderiam se dever ao substrato indígena em virtude das diferenças linguísticas substanciais existentes, geralmente apagadas através da categoria supraétnica "índio".

Assim, os textos selecionados de Yonne Leite possuem valor de memória sobre a pesquisa em terras indígenas e registro histórico sobre a conformação mútua dos campos da Linguística e da Etnologia no Brasil, além das discussões específicas sobre as línguas tapirapé e araweté que beneficiariam estudiosos dos povos Tupi.
No entanto, os artigos conduzem ainda o leitor para a reflexão sobre o papel político do estudo das línguas indígenas no Brasil: atores, motivações e implicações, o que só aumenta o alcance e a importância da obra de Yonne Leite para pesquisadores das duas disciplinas.

DOI http://dx.doi.org/10.1590/0104-93132015v21n1p226

ROCHA, Lia de Mattos. 2013. Uma favela "diferente das outras"? Rotina, silenciamento e ação coletiva na favela do Pereirão, Rio de Janeiro. Rio de Janeiro: Quartet \& Faperj. 292 pp.

\section{Daniela Fichino}

Pesquisadora na Justiça Global

Uma favela típica da exceção, um caso particular do possível, "bom para pensar". No Rio de Janeiro anterior ao início da implantação das Unidades de Polícia Pacificadoras (UPPs), a favela do Pereirão poderia ser tomada como uma "ilha de tranquilidade" em meio a um cenário de incursões policiais e confrontos - como uma favela "diferente das outras"? Que oportunidades e obstáculos esta suposta "tranquilidade" ofereceria à ação coletiva dos moradores e à atuação das organizações locais e supralocais que existem no âmbito da favela? Seria um cenário suficiente para afastar as representações que estigmatizam os moradores e os confundem com traficantes de drogas e, consequentemente, alterar o grau de interlocução possível que detêm no espaço público?

Tais questões, aqui simplificadamente colocadas, são o ponto de partida para o cuidadoso trabalho de pesquisa realizado por Lia Rocha na Vila Pereira da Silva, ou simplesmente "Pereirão", favela localizada na zona sul da cidade do Rio de Janeiro. Dialogando com uma extensa 